\title{
Este não é um filme de ficção: notas sobre o som em falsos documentários de horror
}

\author{
This is not a fiction film: notes on the sound of found \\ footage horror films
}

Rodrigo Carreiro

Professor do Programa de Pós-Graduação em Comunicação da Universidade Federal de Pernambuco (UFPE), doutor e mestre pela mesma instituição

Resumo: Este artigo pretende descrever e analisar os padróes recorrentes no uso do som em falsos documentários de horror, cuja produçáo vem se expandido desde o final dos anos 1990. A partir da análise de um grupo de filmes do subgênero, procuramos lançar luz sobre a estreita relação entre a verossimilhança documental de alguns padróes sonoros e a produção de sentimentos de medo e repugnância nos espectadores.

Palavras chave: "Horror"; "documentário"; "estudos do som"

Abstract:This paper aims to describe and analyze some recurring patterns in the use of sound in found footage horror films, whose production has been expanding since the late 1990s. From the analysis of a group of films, we try to explain the close relation between the documental verisimilitude of some sound patterns and the production of feelings of fear and disgust in film viewers.

Keywords: "Horror"; "documentary"; "sound studies" 


\section{Introdução}

Narrativas ficcionais codificadas como documentários constituíram, nas três décadas seguintes à virada dos anos 1950-60, uma parcela muito pequena da produção fílmica internacional. Desde o final dos anos 1990, contudo, a quantidade dessas realizaçôes tem crescido exponencialmente à medida que cineastas de várias partes do mundo passaram a explorar cada vez mais um formato narrativo específico, encravado numa zona híbrida entre a ficção e o documentário. Chamada por parte da imprensa cinematográfica estadunidense de found footage genre e identificada por muitos críticos como um subgênero do cinema de horror, essa produção é constituída por filmes que combinam forma documental e conteúdo ficcional. Os filmes que compóem esse subgênero são construídos, parcial ou totalmente, a partir de falsos registros amadores de fatos extraordinários, produzidos com a intençáo de parecerem autênticos. A estilística documental utilizada nesses filmes valoriza certa imperfeição formal, de modo a gerar no espectador a ilusão (muitas vezes consentida) de que cada um deles constitui um documento histórico - um registro não encenado de um pedaço de realidade. Entre os títulos mais conhecidos do subgênero estão $A$ Bruxa de Blair (Blair Witch Project, Eduardo Sánchez e Daniel Myrick, 1999), [Rec] (Jaume Balagueró e Paco Plaza, 2007), Cloverfield-Monstro (Matt Reeves, 2008), Diário dos Mortos (George Romero, 2007) e Atividade Paranormal (2007, Oren Peli). Graças ao baixo custo de produção, filmes de found footage têm sido realizados muitas vezes fora dos grandes estúdios, em países como Índia, Brasil, Noruega, Espanha, Dinamarca, Austrália, Costa Rica e Bélgica.

O uso da forma documental acoplada a enredos ficcionais inseridos no gênero horror existe historicamente desde 1980, ano em que foi lançado o pioneiro filme italiano Canibal Holocausto (Cannibal Holocaust, Ruggero Deodato). Nos vinte anos que se seguiram, lançamentos ocasionais tomaram emprestada a combinação de estilística documental com narrativa ficcional de horror. Estatisticamente, porém, a produção desse tipo de filme só veio a ganhar status de subgênero a partir do sucesso conquistado por A Bruxa de Blair.

A relação custo-benefício deste filme estadunidense, que foi produzido com US\$ $30 \mathrm{mil}^{1}$ e arrecadou US\$ 248,6 milhóes em bilheterias internacionais, foi um dos fatores que impulsionou a produção de mais filmes seguindo a mesma receita estética. Além disso, o longa-metragem mostrou que o baixo custo podia se estender também, neste subgênero específico, a área de marketing. A Bruxa de Blair foi um dos primeiros lançamentos a aproveitar o potencial viral da Internet. Graças à websites falsos,

\footnotetext{
${ }^{I}$ Este valor foi gasto pelos produtores nas etapas de pré-produção e filmagem, tendo custeado ainda o primeiro corte do filme. Depois de ser exibido no Festival de Sundance de 2009, o longa-metragem foi adquirido pela distribuidora Artisan Films, que gastou mais US\$ 450 mil para pagar um novo sound design, correçáo de cores, finalização e telecinagem para o formato 35 mm (THE BLAIR WITCH PROJETC FAQ).
} 
parte da audiência acreditou que as imagens dos três estudantes de Cinema perdidos num bosque e, aparentemente, perseguidos por algo de natureza sobrenatural seriam um registro real dos últimos dias de vida do trio. A estilística documental adotada pelos diretores mostrou-se primordial para o sucesso alcançado.

Tudo isso, associado a necessidade de renovação nas convençóes narrativas do cinema de horror - cujos diretores precisam encontrar novos modos de acionar nos espectadores respostas emocionais envolvendo sentimentos de medo e repulsa, centrais para provocar a sensação física e emocional que empresta o nome ao gênero fílmico (CARROLL, 1999, p. 30) - ajuda a explicar o aumento da produção de falsos documentários. Especialmente, quando vinculados a enredos ficcionais que lidam com o afeto do horror.

A popularização dos falsos documentários de horror, conforme descrita acima, tem sido estudada principalmente de pontos de vista externos ao filme em si. Os aspectos extratextuais, particularmente relacionados ao contexto de divulgação, têm chamado a atenção de pesquisadores como Jane Roscoe (1999, 2002) e Kim Newman (2011). Poucos estudiosos voltaram sua atenção para os aspectos estilísticos do subgênero, ou seja, para a maneira como os diretores desses filmes têm manipulado elementos da linguagem cinematográfica para gerar o afeto do horror, essencial para a experiência do espectador.

O objetivo deste artigo é investigar as estratégias criativas utilizadas no som desses filmes. Partimos da constatação de que os recursos sonoros mais estáveis, nesses filmes, buscam provocar no público a impressão de verossimilhança documental, crucial para aproximar a narrativa da realidade ontológica do espectador. Esse efeito de real (BARTHES, 1972) tem se mostrado importante para gerar, em membros da audiência, as sensaçôes de medo e repulsa que provocam o afeto do horror.

Para alcançar essa meta, procuramos identificar e catalogar a produção internacional de falsos documentários em longa-metragem disponível no mercado de vídeo doméstico, chegando a um conjunto de 180 títulos produzidos entre os anos de 1999 e 2013. A análise desse conjunto de títulos nos permitiu identificar padróes recorrentes no uso dos três componentes do som no cinema (voz, música e efeitos sonoros), os quais serão analisados a seguir.

\section{Um conflito estilístico}

O fio condutor de nossa investigação está num conflito estético existente entre dois princípios cruciais da estilística cinematográfica: a legibilidade narrativa e a verossimilhança documental. Como observou Rick Altman (1992), esse conflito atravessa transversalmente a maioria dos 
filmes. Jeffrey Ruoff (1992, p. 217) assinalou que os dois princípios são incompatíveis, de modo que as decisóes criativas tomadas por um cineasta oscilam entre ambos, por razões tanto estéticas quanto históricas.

Pode-se dizer que o sistema narrativo clássico, consolidado desde a década de 1910, costuma favorecer a legibilidade: a compreensão do enredo é mais importante do que o naturalismo das situaçóes dramáticas apresentadas nas diversas cenas e sequências que o compóem. Ainda que certo grau de verossimilhança seja necessário para gerar a aparência de realismo, a legibilidade das informações sonoras e visuais costuma ser mais destacada. Para a grande maioria dos cineastas, o espectador precisa acompanhar a progressão dramática do enredo. E ele só pode fazer isso quando consegue entender aquilo que vê e ouve.

O conflito entre legibilidade e verossimilhança se manifesta nas mais diversas áreas de produção. No roteiro, por exemplo, um almoço deve ser condensado dentro de uma cena de três a cinco minutos, quando na vida real demoraria muito mais. A sensação de verossimilhança não resiste a um exame detalhado. Situaçôes dramáticas, diálogos e aspectos técnicos sofrem ajustes para que possam ser acomodados dentro das exigências de legibilidade. Permitir que o espectador processe e compreenda as informações recebidas é mais importante do que manter o realismo das situaçóes.

O choque entre verossimilhança e legibilidade se manifesta de forma especialmente saliente no uso do som. Rick Altman descreveu essa tensão de maneira detalhada. Ele observou que, em filmes de ficçáo, o espectador precisa escutar os sons do filme - em especial os diálogos com bastante clareza, para poder acompanhar a progressão dramática do roteiro (ALTMAN, 1992). O grau de legibilidade necessário para prender a atenção da plateia chega, em algumas situaçôes, a ser antinatural. É comum, por exemplo, que a plateia possa ouvir dois personagens conversando dentro de uma boate ou show musical. É necessário um cuidadoso trabalho de desenho e mixagem sonoros para que seja possível incluir nos filmes de ficção todos os ruídos ambientes (necessários para manter a coerência da banda sonora com seu correspondente imagético) sem que se perca a legibilidade da voz.

Nos falsos documentários de horror, esta convenção da ficção cinematográfica, tâo firmemente estabelecida, colide de modo mais agudo com o segundo princípio estilístico fundamental: a verossimilhança documental daquilo que se pode ouvir. Nos documentários, em especial naqueles vinculados aos modos de representação observacional e/ou participativo (NICHOLS, 2005, p. 136), o equilíbrio entre legibilidade e verossimilhança difere dos filmes de ficçáo. A verossimilhança ganha importância, pois câmera e microfone captam momentos únicos, que não podem ser encenados ou repetidos. Como nos diz Bill Nichols: "A tradição do documentário 
está profundamente enraizada na capacidade de ele nos transmitir uma impressão de autenticidade" (NICHOLS, 2005, p. 20). Essa impressão de autenticidade está diretamente relacionada à verossimilhança daquilo que o espectador vê e ouve.

Por tudo isso, percebe-se que um filme só está apto a sustentar a condição documental se exibir imperfeições técnicas no registro sonoro e imagético, aquilo que Fernão Ramos chama de "ênfase na indeterminação da tomada” (RAMOS, 2008, p. 25), ao se referir a texturas estilísticas típicas do documentário no campo da imagem, como câmera tremida, perda de foco e iluminação deficiente. Uma imagem perfeita demais, claramente encenada, destruiria a ilusão (ainda que consentida) do espectador sobre estar assistindo a um registro do real. $\mathrm{O}$ mesmo pode ser dito em relaçáo ao som. Diretores de falsos documentários de horror, por consequência, são obrigados a sacrificar um pouco da legibilidade para alimentar a crença nas propriedades documentais das imagens e sons que manipula.

Transpondo esse raciocínio para o campo do som, é possível perceber que um falso documentário exige certo grau de "sujeira" na apresentação sonora, capaz de reforçar a credibilidade no estatuto amador daqueles registros. Se quisesse manter na plateia a crença (ou uma forma de ilusão consentida) de estar assistindo ao registro amador de uma ocorrência verdadeira, o diretor de um filme de found footage precisaria preservar algumas imperfeiçôes na organização e apresentação dos sons.

Antes de descrever os padrôes sonoros mais recorrentes que encontramos nos falsos documentários, duas tarefas preliminares se impóem: é preciso adotar uma definição estável do horror enquanto gênero fílmico, e explicar brevemente quais são as principais características de estilo, na área da imagem, do subgênero estudado.

Estabelecer uma definição estável de cinema de horror é importante para circunscrever, com precisão, o corpus da pesquisa. Essa tarefa não é, como pode parecer, das mais simples. Como ocorre com todos os gêneros fílmicos, o horror possui fronteiras elásticas, pouco discerníveis, e isso dificulta o trabalho de classificar aqueles filmes que se posicional nesses lugares fronteiriços. Esse é o caso, por exemplo, do muito conhecido Psicose (Psycho, Alfred Hitchcock, 1960), que alguns estudiosos classificam como filme de horror, e outros não. Além disso, há divergências entre os pesquisadores também nos critérios que determinam o pertencimento ao gênero.

O filósofo Noël Carroll, um dos primeiros e mais influentes pesquisadores a elaborar uma teoria do horror (ou, mais precisamente, uma filosofia do horror, como indica o título do longo ensaio que escreveu em 1990 sobre o gênero), estabelece dois critérios principais para classificar um filme na categoria do horror. O primeiro critério, e mais importante, estaria na mobilização afetiva dos personagens. Para Carroll, um filme só 
pode ser considerado de horror se o sentimento que leva este nome for a principal emoçáo provocada pela ação vista no filme em seus personagens - e, por consequência, também nos espectadores. Esse raciocínio nos leva à conclusáo inevitável de que os padrôes de estilo que aparecem com mais frequência nos filmes de horror estão lá para provocar (ou ajudar a sustentar) no espectador a emoção do medo e/ou o sentimento de repulsa.

O segundo critério de pertencimento ao gênero do horror, para Noël Carroll, é a presença no filme de seres ou criaturas que o filósofo chama de "monstros" (CARROLL, 1999, p. 29). A teoria original de Carroll considera como monstros apenas seres que não pertencem ao universo em que vivemos, seres extraordinários. A maior parte dos pesquisadores que se lançou à tarefa de investigar a ontologia do horror concorda com Carroll, mas alguns alargam o conceito de monstro cunhado por ele. É o caso de Carol J. Clover (1993), que classifica como monstros os seres humanos com desvios violentos de comportamentos, como assassinos seriais e psicopatas, e também os seres naturais nascidos com alguma disfunção orgânica que os torna mais violentos e/ou perigosos (seriam os casos de criaturas como King Kong, Godzilla ou o tubarão branco que protagoniza o filme homônimo de Steven Spielberg).

Para efeito desta pesquisa, a definição de horror adotada combina esses dois critérios: o afeto do horror (o medo, acompanhado por repulsa em algum grau) e a presença de pelo menos um monstro, no sentido mais largo do termo.

\section{A música}

A música é, talvez, a área em que o som dos falsos documentários de horror gera padróes recorrentes mais fáceis de identificar. Existem, de modo geral, três opçôes estilísticas à disposição dos diretores. $\mathrm{Na}$ maioria dos filmes, não existe música extra-diegética. A única música que os membros da plateia podem ouvir é diegética - ou seja, é executada dentro da diegese, e os personagens também podem escutá-la. Apenas quando algum personagem escuta o rádio do carro (como ocorre em A Bruxa de Blair), póe um CD para tocar ou canta alguma canção, personagens e espectadores ouvem música. [Rec], [Rec 2] (Jaume Balagueró e Paco Plaza, 2009), Alien Abduction - Incident at Lake County (Dean Alioto, 1998) e O Caçador de Troll (Troljegeren, André Øvredal, 2010) são alguns dos falsos documentários que seguem essa opção estilística. O uso de música incidental - aquela

\footnotetext{
${ }^{2} \mathrm{O}$ crescendo é um recurso instrumental em que o instrumentista amplia progressivamente a intensidade da nota musical. No diminuendo, ocorre o contrário, a intensidade diminui. $\mathrm{O}$ glissando é um recurso de execução instrumental no qual o instrumentista percorre a distância entre a nota inicial e a final passando por todas as notas intermediárias.
} 
de que somente o espectador tem consciência, procedimento que consiste em uma das convençóes mais tradicionais do cinema narrativo clássico - é pouco frequente nos falsos documentários de horror.

Há dois tipos de exceção a essa regra. A primeira pode ser encontrada nos falsos documentários de cunho metalinguístico, que explicitam procedimentos de edição e montagem (ou seja, filmes cujo processo de organização criativa aparece dentro do próprio enredo). Em Canibal Holocausto, apresentado como um documentário editado a partir de registros deixados pelos integrantes desaparecidos de uma expediçáo às selvas da América do Sul, as cenas que se passam na floresta são sonorizadas com música tribal, executadas com tambores e flautas de madeira. O filme, porém, é apresentado como um documentário editado por uma emissora de televisão. Ao longo de toda a sua duração, inclusive, os personagens responsáveis pela montagem do documentário se questionam sobre seus procedimentos.

O padrão recorrente utilizado pelo diretor Ruggero Deodato - e repetido por George Romero, entre outros, em Diário dos Mortos - está sintetizado na decisáo narrativa de incluir uma ou mais cenas que assinalam e explicam o uso de música na pós-produção. Essas cenas são escritas e incluídas na edição final para justificar uma suposta violação da estilística documental. Ainda que o uso de música em documentários seja bastante comum, não o é nos documentários realizados dentro ou com predomínio do modo de representação observacional (NICHOLS, 2005, p. 135).

Essa violação aproxima os filmes da estilística do cinema ficcional clássico, algo que os diretores de falsos documentários não desejam. O apelo à metalinguagem, nesse caso, acaba se mostrando uma circunstância atenuante, que afasta novamente os filmes do padrão estilístico seguido pelo cinema ficcional (e empurra os filmes para uma estética mais próxima do modo de representação participativo). Além disso, esse tipo de uso da música tem sido evitado porque chama a atenção do espectador para a existência de uma instância narrativa (que organiza e estrutura as situaçóes dramáticas vistas na tela) oculta, situada fora da diegese.

A segunda exceção à regra está na utilização do estilo drone como trilha musical extra-diegética. A música drone consiste em um estilo minimalista, quase sempre eletrônica, que enfatiza notas sustentadas ou repetidas por longos períodos de tempo, moduladas essencialmente por meio de efeitos de crescendo, diminuendo e glissando ${ }^{2}$.

Por não possuir uma marcação rítmica constante, a música drone possui forte característica de imprevisibilidade, permitindo aos cineastas que a usem de modo a adicionar tensão e suspense. E essas são características muito perseguidas por diretores de filmes de horror. Além disso, por

${ }^{2} \mathrm{O}$ crescendo é um recurso instrumental em que o instrumentista amplia progressivamente a intensidade da nota musical. No diminuendo, ocorre o contrário, a intensidade diminui. O glissando é um recurso de execuçáo instrumental no qual o instrumentista percorre a distância entre a nota inicial e a final passando por todas as notas intermediárias. 
consistir, muitas vezes, de simples notas repetidas e manipuladas eletronicamente, sem linhas melódicas repetidas, a música drone é mais difícil de ser percebida como música pelo espectador. Isso evita a necessidade de inclusão de cenas que justifiquem o uso da música. Noroi (The Curse, Kôji Shiraishi, 2005), The Poughkeepsie Tapes (John Erick Dowdle, 2007), Lake Mungo (Joel Anderson, 2008) e The Tunnel (Carlo Ledesma, 2011) são alguns exemplos de filmes de found footage que usam a música drone.

\section{A voz}

O elemento sonoro mais proeminente no cinema narrativo clássico é a voz humana. Há mais de uma razão para isso, mas a mais importante está diretamente relacionada ao conflito entre legibilidade e verossimilhança. A principal ferramenta narrativa disponível aos diretores e roteiristas de filmes para permitir ao público acompanhar a progressão dramática do enredo é a palavra. Por meio de diálogos, monólogos e da ocasional narração em voz over ou off, os espectadores recebem informaçóes constantes que lhes orientam sobre o andamento da trama. Por conta disso, o trabalho de mixagem quase sempre eleva os níveis de intensidade da voz acima dos demais componentes da trilha sonora (música e ruídos). Esse procedimento técnico é imposto pelo predomínio da legibilidade sobre a verossimilhança.

Em filmes narrativos, há todo um cuidado para que as vozes dos atores estejam facilmente compreensíveis. O predomínio da legibilidade pode ser confirmado em situaçóes dramáticas que, se apresentadas de forma realista, apresentariam dificuldades para que as vozes dos personagens fossem ouvidas. Cenas que se passam dentro de ambientes barulhentos, como um bar ou boate, um estádio esportivo ou um show musical, costumam ser cuidadosamente mixadas para que o espectador ainda possa ouvir com clareza o que dois personagens do filme estão conversando.

Dois fatores dificultam esse privilégio da legibilidade da voz nos falsos documentários de horror. O primeiro deriva das limitaçôes técnicas oferecidas pelas condiçóes precárias do registro documental. Em teoria, nos documentários observacionais ou participativos, os responsáveis pela captação sonora não têm a possibilidade de repetir sequências para garantir a perfeita qualidade sonora. Muitas vezes, os técnicos de som precisam manejar o equipamento sem conseguir se posicionar de forma adequada para efetuar um bom registro dos sons. Ademais, se a captação de áudio fosse limpa demais, perfeita demais, não pareceria um registro do real. São necessárias imperfeiçóes para que o público aceite o que vê como registro do real. Essas imperfeições reforçam a verossimilhança e oferecem uma impressão maior de realidade.

O conflito encontra, nessa situação, seu maior impasse. $\mathrm{O}$ desafio dos diretores de falsos documentários de horror é o seguinte: eles precisam 
garantir um nível elevado de legibilidade da voz dos atores, porque sem isso a plateia não poderá acompanhar a progressáo dramática da estória; e por outro lado, também devem cuidar para que haja imperfeiçóes, lacunas e defeitos de captaçáo em quantidade suficiente para que a audiência veja confirmada a impressão de estar diante de uma janela para o real. Esse equilíbrio é delicado e difícil de alcançar.

Desse modo, virtualmente, todos os falsos documentários seguem roteiros em que o improviso dos diálogos, ou pelo menos uma impressão forte de improviso, é adotado como norma. Os personagens param frases pela metade, emitem e corrigem raciocínios truncados, dizem palavras erradas, atropelam as palavras uns dos outros, cometem erros de gramática. Nada disso é comum no cinema narrativo clássico, onde as falas dos atores são pausadas e quase nunca se sobrepóem. Na vida real (e nos documentários), porém, essa é a norma. Por isso, os filmes de found footage seguem esse padrão típico da estilística documental.

Um elemento vocal que não falta no subgênero é o grito. Grita-se sempre, e grita-se muito, em falsos documentários de horror. Este padrão recorrente remete a uma convenção do cinema de horror, em cuja experiência afetiva o grito é central (CARREIRO, 2001, p. 45). Se uma condição fundamental para garantir o pertencimento ao gênero é que os personagens da ficção experimentem o afeto do horror, e se é importante que haja empatia entre esses personagens e os membros da audiência, os filmes precisam conter gritos. E contém.

Outro padrão muito explorado em falsos documentários é a utilização de efeitos sonoros localizados nos extremos da escala de frequências captadas pelo ouvido humano ${ }^{3}$ para caracterizar a os efeitos vocais emitidos pelo viláo. Esses timbres, devido a semelhança com os ruídos produzidos por animais ferozes, costumam ser interpretados cognitivamente pelo ser humano como uma ameaça, e é por isso que os vilóes do cinema de horror, de modo geral, abusam de timbres graves ou agudos. Em [Rec], os zumbis foram sonorizados pelo sound designer, Oriol Tarragó, com sons de animais como porcos, galinhas e leóes, muitas vezes modificados eletronicamente para vibrarem em frequências abaixo de $300 \mathrm{~Hz}$ ou acima de $8.000 \mathrm{~Hz}$ (TARRAGÓ, 2010).

Cloverfield também oferece uma clara demonstração de que, se o balanço entre verossimilhança e legibilidade em falsos documentários de horror segue padróes diferentes do cinema ficcional clássico, a segunda não se torna simplesmente mais perseguida do que a primeira. $\mathrm{O}$ ataque do monstro a uma multidão reunida na Ponte do Brooklin, em Nova York, exemplifica isso. São muitos os sons que compóem a cena: gritos de milhares de pessoas, helicópteros, tiros efetuados pelos policiais, rugidos do monstro, sirenes de ambulância, sons de concreto e ferro se chocando ao

${ }^{3} \mathrm{O}$ ouvido humano consegue captar sons localizados entre 20 e $20.000 \mathrm{~Hz}$. 
longo do ataque etc. Mesmo com tamanha cacofonia, e apesar de o registro sonoro estar supostamente sendo feito com o microfone interno de uma câmera amadora de vídeo (ou seja, além de amador, o equipamento ainda é utilizado de modo tecnicamente incorreto), é possível ouvir perfeitamente as conversas entre os personagens principais.

\section{Os efeitos sonoros}

Um dos padrões recorrentes mais incomuns dos falsos documentários de horror diz respeito à distribuiçáo dos efeitos sonoros entre os canais de áudio. Como se sabe, desde o início a década de 1990 os sound designers dispóem de pelo menos seis canais independentes, onde podem distribuir as informações sonoras ${ }^{4}$. No cinema ficcional, a tendência dos profissionais que planejam e criam sons consiste em utilizar o máximo possível esses seis canais, para gerar um ambiente sonoro tridimensional. No entanto, a aplicação deliberada dessa tecnologia em filmes de found footage tem se revelado um problema, mais uma vez ligado ao conflito entre verossimilhança e legibilidade.

Nesses filmes, que são compostos em grande parte por cenas supostamente captadas com equipamentos de tecnologia não profissional (e muitas vezes operado por amadores), a inclusão de som cristalino em seis canais pode destruir a credibilidade do registro documental. Oriol Tarragó, sound designer de [Rec], afirma que a decisão de distribuir todos os sons apenas nos canais dianteiros - com ênfase no canal central - e pouco utilizar os canais surround foi tomada nos primeiros estágios de pré-produçáo, e contou com o apoio dos diretores Paco Plaza e Jaume Balagueró: "Apesar de [Rec] ter sido mixado em Dolby Digital 5.1, toda a mistura é bastante central (mono). Nós queríamos transmitir a ideia de que havia apenas um microfone, instalado na câmera, capturando todo o som do filme.” (TARRAGÓ, 2010).

De modo geral, os canais traseiros em [Rec] são utilizados de modo muito discreto, sem que seja possível ouvir neles nada que possa ser enquadrado na categoria que Michel Chion (2011, p. 70) define como som fora de quadro ativo - um som cuja fonte emissora náo apareça na imagem, mas chame a atenção para si, de modo que incite a curiosidade do espectador. Oriol Tarragó usou os canais traseiros para realçar principalmente sons de média ou baixa frequência, quase sempre zumbidos, chiados ou gritos guturais em cenas muito agitadas, em que o espectador dirige a atenção principalmente à imagem, na tentativa de compreender o que se passa na tela.

De modo geral, essa decisão criativa favorece a verossimilhança e causa algum prejuízo à legibilidade dos sons. Se um filme dispóe de menos canais de áudio, isso significa que ele terá menos sons, no geral, pois a sobreposição de frequências sonoras dentro de um mesmo canal costuma provocar o fenômeno acústico conhecido como mascaramento, no qual os sons de frequências semelhantes se anulam, de forma que o ouvinte não consegue distinguir nenhum deles com clareza. 
Um padrão igualmente comum, e que tem relação estreita com o anterior, é o constante uso do aparato de captação de sons. Esse padrão deriva naturalmente de uma condição imposta pelo formato narrativo do subgênero, que é a exigência da presença de pelo menos uma câmera dentro da diegese. Se existe uma câmera registrando a realidade, é natural que exista também um microfone.

Em alguns filmes, nos quais se pode perceber a preocupação dos cineastas em justificar para a plateia a boa qualidade da captação das vozes e ruídos naturais, são incluídas cenas em que personagens montam ou corrigem detalhes de posicionamento dos equipamentos de áudio. Isso ocorre, por exemplo, em $O$ Caçador de Troll, numa cena em que um dos protagonistas instala um potente microfone de lapela em si mesmo para tentar captar a voz de outro personagem que não deseja ser gravado.

Esse raciocínio nos leva, ainda, a outro padrão: a presença constante, nos falsos documentários, de personagens que trabalham na área do audiovisual. Em $O$ Último Exorcismo (The Last Exorcism, Daniel Stamm, 2010), uma equipe de documentaristas registra a rotina de um pastor que percorre fazendas na região do meio oeste estadunidense, realizando falsas cerimônias de exorcismo. Documentaristas também são protagonistas de $A$ Bruxa de Blair, O Caçador de Troll, Canibal Holocausto, The Tunnel e [Rec], entre outros.

Em todos os filmes citados no parágrafo anterior, existe ao menos um personagem que exerce a função de técnico de som direto, ou seja, tem o dever profissional de registrar os sons dos acontecimentos captados também pela câmera. A presença deste personagem tem uma função simbólica importante: ele justifica a boa qualidade sonora do filme, já que em tese possui a expertise necessária para evitar problemas graves de legibilidade sonora. Isso ocorre também, naturalmente, no campo da imagem. A presença de profissionais do audiovisual na diegese justifica, para o público, não apenas a boa qualidade do registro do real, mas também o fato de as câmeras e gravadores de som continuarem ligados. Mesmo quando a situação registrada ficou tão dramática e perigosa que um personagem leigo, supostamente, teria deixado em segundo plano qualquer preocupação com a qualidade do registro audiovisual.

Em filmes de found footage, também é comum que os sound designers explorem sons e texturas que, nos filmes de ficção tradicionais, seriam compreendidos como defeitos: eco, reverberaçáo, microfonia, sons de respiração ofegante, sinal saturado do microfone, distorçóes magnéticas, roupas roçando no microfone de lapela etc. Em O Misterioso Assassinato de uma Família (Atrocious, Fernando Barreda Luna, 2011), uma rede subterrânea de túneis de concreto e os amplos cômodos de uma mansão centenária fazem, respectivamente, as vozes ressoarem com profundidade e reverberação incomuns. Já em $[R e c]$, pancadas no microfone embutido na câmera provocam microfonias e "quedas" do sinal de áudio por alguns segundos, fazendo o espectador perder a referência auditiva por alguns segundos e aumentando ainda mais a tensáo acumulada. No caso desse filme espanhol, todos os "defeitos" sonoros foram cuidadosamente produzidos em estúdio: "microfonias, quedas de microfone e ruídos de manuseio em geral" (TARRAGÓ, 2010). 


\title{
Conclusão
}

Quase todos os padróes de som recorrentes em falsos documentários de horror, com poucas exceçôes, têm relação direta com o conflito entre legibilidade e verossimilhança. De modo geral, eles decorrem da necessidade que os diretores e sound designers desses filmes têm de enfatizar a impressão de documento histórico, de registro do real, que eles oferecem aos espectadores. É possível afirmar, de fato, que as decisóes criativas relacionadas ao som decorrem, em grande medida, de uma característica central compartilhada por todo o subgênero: a presença de uma câmera (ou mais de uma) dentro da diegese, um aparato capaz de oferecer ao público desses filmes uma janela para o real, ou melhor, para um simulacro deste. Bill Nichols descreve assim o impacto da presença da câmera na audiência de um documentário:

\begin{abstract}
A presença da câmera "na cena" atesta sua presença no mundo histórico. Isso confirma a sensação de comprometimento, ou engajamento, com o imediato, o íntimo, o pessoal, no momento em que ele ocorre. Essa presença também confirma a sensação de fidelidade ao que acontece e que pode nos ser transmitida pelos acontecimentos, como se eles simplesmente tivessem acontecido, quando, na verdade, foram construídos para terem exatamente aquela aparência. (NICHOLS, 2005, p. 150).
\end{abstract}

Afora isso, é preciso observar a forte sintonia que existe entre os padrôes recorrentes dos filmes de found footage e a estilística sonora dos documentários que pertencem aos modos de representação observacional e participativo (NICHOLS, 2005, p. 135). Essa sintonia não é coincidência. Os dois modos de representação são aqueles que oferecem ao espectador a impressão mais forte de registro da realidade. A verossimilhança desse registro documental é crucial para gerar na audiência aquilo que Carl Plantinga chamou de "postura assertiva" (PLANTINGA, 1997, p. 40).

Para Plantinga, ainda que cada membro da audiência saiba que um registro documental pode ser construído da mesma forma que uma ficção audiovisual o é, existe uma crença profunda de que esse tipo de representação seja capaz de oferecer acesso ao real. A consequência disso é que essa crença profunda existe e se manifesta cognitivamente, mesmo de modo inconsciente, nos espectadores, produzindo aquilo que Roland Barthes (1972) chamou de "efeito do real". Ou seja, ainda que a plateia tenha consciência de que está assistindo a uma ficção, seus membros conservam parte da reação afetiva natural daqueles que imaginam estar acessando uma janela da realidade e assistindo a eventos ocorridos na mesma realidade ontológica. 
Nesse sentido, é possível afirmar que a produção de um efeito de real mais duradouro, gerado ou reforçado pela aparência de verossimilhança documental existente nos padróes de uso do som descritos ao longo deste artigo, é condição que provoca ou amplia nos espectadores desses filmes, o afeto do horror. Este afeto, por sua vez, consiste em condição fundamental para a eficiência de um enredo desse gênero fílmico (CARROLL, 1999, p. 30). Portanto, o efeito de real produzido pelos padróes sonoros exerce papel importante na experiência afetiva do medo, crucial para o gênero do horror, dentro de falsos documentários.

\section{Referências Bibliográficas}

ALTMAN, Rick (Org.). Sound Theory, Sound practice. New York: Routledge, 1992.

BARTHES, Roland. “O efeito de real”. In O Rumor da Língua. São Paulo: Martins Fontes, 2004.

BORDWELL, David; STEIGER, Janet; THOMPSON, Kristin. The Classical Hollywood Cinema: Film Style \& Mode of Production to 1960. New York; Columbia University Press, 1985.

CARREIRO, Rodrigo. Sobre o som no cinema de horror. Revista Ciberlegenda, Rio de Janeiro, Universidade Federal Fluminense, volume 24, número 1, Pp. 43-53, agosto de 2011.

CHION, Michel. A audiovisão. Lisboa: Edições Texto \& Grafia, 2011.

NICHOLS, Bill. Introdução ao documentário. Campinas: Papirus, 2005.

PLANTINGA, Carl. Rhetoric and representation in nonfiction film. Cambridge: Cambridge University Press, 1997.

RAMOS, Fernão Pessoa. Mas afinal... o que é mesmo documentário? São Paulo: Editora Senac, 2008.

RUOFF, Jeffrey K. Conventions of sound in documentary. In: ALTMAN, Rick (org.). Sound theory, sound practice. New York: Routledge, 1992. Pp. 217-234.

TARRAGÓ, Oriol. Exclusive interview with Oriol Tarragó. Designing Sound. Blog. Disponível em: http://designingsound.org/2010/04/exclusive-interview-with-oriol-tarrago-sound-designer-of-rec-and-rec-2/. Acesso em: 09 de janeiro de 2013. 